\title{
Effect of Financial Measures on the Export Competitiveness of Mongolian Livestock Products
}

\author{
Dolgion Naranbat \\ School of Economics and Management \\ Tianjin University of Science and Technology \\ Light Industry Technical Economy \\ Tianjin, China
}

\begin{abstract}
The agricultural sector is unique in comparison to other industries. Most of the households in Mongolia are having agricultural workers, most of who are in the local traditional animal husbandry industry. Local animal husbandry is a traditional industry that is adapted to the natural features of the climate on which it is dependent. The mining sector is a highly volatile sector which can contribute significantly to sustainability. The competitiveness of the agricultural sector is widely measured using an International Index comparison of horse meat, beef, leather and cashmere. Cashmere products have a comparative advantage.
\end{abstract}

Keywords-Mongolian livestock; financial measures; livestock product; the effect of Mongolian livestock

\section{INTRODUCTION}

The agricultural sector is unique in comparison to other industries. Developing the agricultural sector: firstly, food security should be provided; secondly, the livelihoods and revenues of the local population should be supported; thirdly, land resources should be efficiently used. In some studies, most of the households in Mongolia are agricultural, and growth in the agricultural sector and other contributing factors has been shown to alleviate poverty.[1] Animal husbandry is a traditional industry that is adapted to the natural features of the climate on which it is dependent. The mining sector, which is highly volatile economically, is one of the sectors that can contribute significantly to sustainability.

The agricultural sector of our country has been around $13 \%$ of GDP for the last 5 years and accounts for about $30 \%$ of the workforce with $36 \%$ of households in rural areas. These are directly affecting the livelihoods of these people. Economies are intense as a result; the competitive situation of the agriculture sector is weakening I can see. For example, NSO data shows that in 2000, agriculture which accounted for $27 \%$ of GDP fell to $14 \%$ in 2014. In addition, Mongolia's competitiveness report is that in the local economy the competitiveness of aimags is dominated by agriculture, especially livestock dominated the indicator is lower than the other aimags. This study examines the competitiveness of the agricultural sector in Mongolia and the impact of these factors and to take measures to improve agricultural productivity. Despite overgrazing and overloading some studies have been developed (SDC, 2015), to improve competitiveness and living standards in the industry but this study did not address this topic.[2] The first chapter is the current state of agriculture, competitiveness, the international experience of agricultural development, and final conclusion.

\section{COMPETITIVENESS OF THE AGRICULTURE SECTOR}

Competitive production, demand, quality, and quantity requirements of the business will enable the sector to continue to be profitable over time.[3] To be competitive, entrepreneurs with the same quality standards at competitive prices are able to offer a product or service that meets the requirements the resources available to meet the available resources. Competent enterprises and countries generally have products which are low cost, or at the level of price and cost. It produces better quality. A country's competitiveness depends on its resources, technology, budget, monetary policy and exchange rate. For example, the enterprise unit tax and high-interest rates, will lead to a poorly competitive economy. But when the land, labor, capital costs are low, competing countries with better technology and competitiveness will have a better ability. These competitiveness standard test results concentrate on inputs, production inputs, product quality, price and comparisons of productivity variables. To define the competitiveness of the agricultural sector, as well as markets, food conversion and climate change adaptability, are required. An agricultural product in terms of competitiveness, sub-sectors (animal husbandry, cereals, food and vegetables, etc.) and geographical locations is quite complicated and thus it is necessary to study. For example, in agriculture the competitiveness of the product is the size of the area and the farm, structure, productivity, distances from markets and price changes, resilience, Human Resources (Skilled Workforce, Marketing) capacity, technological advancement, product quality, transportation cost, rules and policies (budget, foreign trade, industry, etc.) Described (Janet Dwyer et al, 2012).

There are two main roles that negatively affect the competitiveness of the agricultural sector. Firstly, suppliers and suppliers in the industry farmers are marketers because they are centralized they are low in power. The number of 
producers of most agricultural products is very high but there are many suppliers of the required ingredients for their production - fertilizers, seeds, machinery and animal health products and loans suppliers are concentrated. Also, for the products from the agricultural producers, the buyers are small and concentrated. In other words, perfect competitive prices are not comparable to those of the sector, which are not oligopolistic. They sell their products to the market and for them it is not possible to influence and create a competitive edge. Secondly, as well as market conditions for agricultural producers in addition there are long-term cycles, which are subject to constant change. This poses a significant risk to small and medium businesses in the agricultural sector. If they do not have much investment in research and development they cannot be sustainable.[4] The imperfect agricultural market is to support sustainable competitiveness by reducing the situation, and the efficiency and productivity of the sector need to increase. Innovation is a long-term agricultural sector sustainability, and risk management capability. Change in the traditional approaches to technological and management change but the modern trend is to run entrepreneurship ability to improve skills and skills and innovate and institutionalize and focus on policy innovation.[5] Improvements in the competitiveness of the agricultural sector opportunities are discussed further in chapter three. The following section looks at the current situation and competitiveness of the Mongolian agricultural sector and an overview of the capability of an agricultural product and export advantage determined using the RCA index and increase in exports of the product study opportunities.

The current situation and competitiveness of the Mongolian agricultural sector the in the economy of Mongolia is high. Production of agricultural products over the last 25 years amounts to $21 \%$ of GDP. $83 \%$ of Mongolian agriculture production is traditionally pastoral livestock husbandry (NSO, 2014).

The agricultural sector accounted for $12 \%$ of GDP in 1990. In the early 1990's other sectors fell sharply during the economic downturn. 1996 was a slow recovery in other sectors during the transition period the share of GDP in the sector increased to $38 \%$. In recent years the mining sector is growing rapidly, and in 2000-2002 and dozed in 2010 down to $14 \%$ GDP in 2014.

\section{A. Animal Husbandry (MAA)}

The Mongolian economy has grown by $4.5 \%$ on average over the last 25 years, and $5.4 \%$ from other sectors. In any sector, the average growth is lower than that of other sectors and is more volatile. For instance, during the winters of 2000-2002, 11 million animals died and the total number of livestock decreased by $30 \%$. So that's it and 16, 19 and $11 \%$ respectively. It was also in 2010 that more than 10 million livestock or $26 \%$ were lost. The manufacturing sector decreased by $17 \%$.

Production of mutton in 1989-2014 by comparing prices at 2010 increased by 1.9 trillion MNT. The number head of livestock during this period grew by 2.1 times, or 27 million, reaching 52 million, which means that the animals owned by herdsmen as a result of privatization. Growth in this category of goat population was 17 million or 4.4 times. Re-growth has been a major factor. As the number of goats increased sharply, the market migration of cashmere to the credit system and the release of foreign trade exports at high prices, and goat yields are due to the fact that more livestock were consumed. The number of horse grew by $36 \%$ to 3 million and cattle by $27 \%$ to 3.4 million. Unfortunately, camel numbers decreased by $37 \%$ to 0.349 million.

\section{B. Exports and Imports of AA Products}

The main exports of meat, cashmere and hides constitute $11 \%$ of total exports over the last 20 years. As of 2014, USD 325 million agricultural products exported amounted to $5.6 \%$ of total exports of which, goat cashmere exports constitute USD 286 million or the majority. In recent years, meat exports have declined dramatically due to the fact that Mongolian meat hygiene does not meet international standards. Also, skins and skins exports have not increased.

Domestic products such as wheat, potatoes, vegetables, eggs, pork, chicken, milk and sour cream total imports of $1.8 \%$ over the past 20 years. As of 2014, the import amounted to the USD 50 million, or $0.9 \%$ of total imports. In recent years, wheat imports have declined substantially in 2014, to USD 11 million. Also, in recent years the value of chicken meat is USD 15 million.

\section{Competitiveness of Agricultural Products}

This section outlines the competitiveness of Mongolian agricultural products analyzed according to the sequence. These include:

- Whether the product's productivity has increased in recent years

- What kind of livestock and crop productivity compare to other countries levels.

- The appreciation of the real exchange rate and its impact on agricultural production

- Production, export, and import of key agricultural products volume, internal and external prices.

\section{The Efficiency of the Agricultural Sector}

Although the livestock sector and herd size have increased substantially, from one animal to another of the benefits have not been increased over the past 25 years. In 1989, 100 animals per animal adding value added would add 60.2 thousand MNT. In 2014 costs are rising, but this is not related to productivity growth. For example, livestock production will be transferred to the price of livestock for 2010. In 1989, value added of MNT was 37.5 thousand per animal. In 2014, this figure was MNT 37.6 thousand.

In the case of the crop sector, it is also possible to examine a hectare of land over time. The harvest increased by more than $40 \%$, from 1989 , when the per hectare value was 711 thousand MNT made in the field, to 1017 MNT in 2014.[6] 


\section{E. International Comparison of Productivity in Agriculture}

Compared to other countries, the productivity of the agricultural sector is quite low. For example, the livestock mortality rate is 6 times higher at 30\%, 20-30 months for slaughter, and 36-46 for beef the number of sheep's 6-8 months and the number are 14 months. Also, despite the recent increase in crop yields, Mongolia is $40-70 \%$ lower than other countries.

1) Real appreciation: Foreign investment in the mining sector since 2000 has increased the rise in export earnings and the inflow of foreign exchange. The real exchange rate has appreciated.

The appreciation of the real exchange rate is a substitute for exports and imports Mongolia was unable to compete as a result of reduced export prices, especially in processing and agricultural production. Real Price Increased in 2000-2008 in the main product, wheat. Domestic yield and imports fell simultaneously. At this time flour imports increased and domestic production declined. Development of agriculture in 2008 starting at the 3rd Campaign at Atar invested heavily in the sector and coupled with real exchange rate, the decline in production of agricultural crops has been reversed.

For 2010, imports of chickpeas, pork and mushroom products have risen sharply. An appreciation of real exchange rate and domestic meat prices overlapped. In addition, to the internationally accepted meat quality standards, domestic consumption is high and domestic meat prices are high the increase in meat prices has been weakened. But exports of Cashmere and other major commodities are denominated in international currencies in international markets. It is realistic that the domestic consumption varies according to the difference between internal and external prices of agricultural products.

Another indicator of competitiveness is internal and external prices. The difference between internal and external prices and exchange rates are connected. If domestic prices rise rapidly, foreign prices will also. If the exchange rate is stable, the price of import of domestically produced goods will be cheaper. Foreign exchange rate or exchange rate weakening will increase the demand for domestic goods, which will make the imported goods more expensive. This trend is apparent in some products. For Cashmere it is low; it was not affected by the exchange rate.

Mongolia has averaged 150 thousand tons of meat per year. It produces 400 tons of it in 2013 none exported in 2014. This is partly due to internal and external the price difference. For example, in 2011 mutton was $4125 \mathrm{MNT} / \mathrm{kg}$. [10], while the world market was at that time the exchange rate was around USD 3/kg [11]. However, in 2012-2013, the average domestic price for meat was 7000 MNT with the exchange rate of price of USD 5/kg. Even in 2014, the exchange rate depreciated the domestic price of sheep to USD $4 / \mathrm{kg}$, but the world market price and the internal and external gap remains high. That is it due to the lack of motivation for exporting meat to companies. They are not motivated.
2) Agricultural products with export advantages: $R C A$ index: This is a comparative advantage in the Mongolian market for the world market. Identifying competitive products and expanding their exports is an opportunity to be considered. Research by Norton (R.Kaplan, D.Norton, 2008) competing for the theory is relatively advantages and competitive advantages, which are related concepts. A comparative advantage of a country is if products are cheap compared to other countries then exports and exported products are relatively high then International trade is profitable - derived from traditional theories. Traditional Theory of Comparative Advantages is often the cost of opportunity and employment-based.[7]

For example, A. Smith (Smith, 1776), J. Miller (Mill, 1848) stated the best country to have an absolute advantage of the basis will know it is important to export low-cost products.[8] This is a deep-seated study by D. Ricardo (Ricardo, 1815). It is best to allocate resources for the most efficient use, they concluded. In that case, the country which produces the lowest cost exporting products can be optimal. Later, E.Hetsher, B.Olin (E.Leamer, 1995) in a new approach to trade theory showed the diversity of resources is most important factor. They will see a lot more of their country export its products. For example, if land resources are high and the country is rich in resources and capital stock, exports from such a country will give it a comparative advantage.

Traditional trading theories are powerful but empirical research is imperative to explain the real picture of trade. Because the relative advantages of many variables observed in the real economy must be considered. Therefore, the relative advantages are an empirical measurement - Revealed Comparative Advantage, RCA. This method of indexing was developed by Balassa.[10] Certainly, the foreign trade of goods and services in that category it has been shown that there are advantages and disadvantages of goods and services. The comparative advantages index is the price, tariff, quality, cost, industrial factors, economic conditions, legal environment, etc. Commercial factors are already considered.

In view of the composition of our export commodities; for mineralization/mining in 2009-2014 the average product is $82 \%$ and agricultural products account for $9 \%$. Other sectors are economically dependent on mining competitiveness for support to stabilize packaging and improve and diversify the export structure. This includes agriculture as one of the sectors that can contribute significantly. So, the country has the advantage of what kind of agricultural products on the world market. It is important to study how competitiveness can be improved. To do this we have calculated the internationally used RCA index.

Specifically, the following methodology is used to estimate RCA for product $\mathrm{j}$ to use.

$$
\text { RCAij }=(E X i j / E X i) /(E X n j / E X n)
$$

Here EXij is the export of $\mathrm{i}$ j products $\mathrm{i}, \mathrm{EXi}$ is the total export of i, EXnj - total export of world $\mathrm{j}$ products, EXn is 
the world's total export expressed. Generally, if the product is exported to RCA> 1 conditions it is advantageous, if RCA $<1$ then the case is in reverse (G.Tasevska \& E.Rabinowicwicz, 2014).

Narrative:

- $\mathrm{RCA}<0.8$ is not comparable

- $0.8<\mathrm{RCA}<1$ is relatively weak

- $\mathrm{RCA}=0.8-1.25$ is comparable with average

- $\mathrm{RCA}=1.25-2.5$ is a strong comparative advantage

- $\mathrm{RCA}>2.5$ is a very powerful comparative advantage

Mongolia originally developed raw leather, wool, animal hair, textile yarns and fabrics. From raw wool, cashmere, and knitwear the advantages of export products are high. Also for carpets and other textile flooring it is comparatively weak but an improved approach is observed. The most comparative advantage of horse meat is for meat and meat products in 2013 when the RCA index was 33.41.

In the end, the frozen beef meat prices had an RCA index of 2.80 in 2011 and 0.42 in 2012 i.e. a decrease. On the other hand, sheep are less competitive as of 2013, the RCA index is 0.03 . Other animals in 2013 the RCA index 8.14. For Bone Cane products, intestines and herbs the RCA index is 0.01 . For the hooves of horses, noses, birds and poultry, the RCA index was 14.79 .

In addition, for 2013, for cattle and horses, raw and processed the leather RCA index was 2.01 and 5.24 respectively. In 2012, sheep and lambs processed skins were 69.30 in 2013 and 61.53 in 2013 respectively decreased. In the case of hides and skins developed by the index 40.50 . From here we see our country's cattle and horses processed skins and sheep skin processing has a very high comparative advantage.

Wool and animal hair, textile yarns and fabrics, originating from them the animals have a comparative advantage. For example, in 2013 The RCA index was 3.11, thin or non-combed with wool coarse animal hair, 1679.00 in wool and non-combed hair, and waste wool, 1.95 for animal combed hair and 107.33 for hair. The comparative advantage for wool, cashmere, and knitwear poor women's cashmere sweater and women's knitted sweaters shirts, polo shirts, jackets, and other knitted garments was high.

3) Competitive or competitive in the world market: Our main importer of agricultural products is our agricultural product average imports from 2010 to 2014, and their global share. The Russian Federation imports cereal frozen beef (USD 2.4 billion), ranking third in Japan (USD 1.3 billion), ranking fourth Korea (USD 1.2 billion), China ranks 11th (USD 0.4 billion) (Appendix, Table 1.5). Italy Imported most horse meat in the world leading to an annual import of USD 113 million. Competitiveness of the agricultural sector and the local population living standards - 588 Bank of Mongolia Research Paper "Brochure-10" Not imported from Mongolia. On average, Russian horse meat imports USD 74 million, or fourth place in the world. During this period, Mongolia, on average, exported 1.7 thousand tons or USD 4.5 million of horse meat.

Importers of animal origin products are Japan, Republic of Korea and China including imports of raw materials and processed skins, such as China. Italy tops the world. Our country exports wool, woolen products and carpets to Korea, China, and the United States. As frozen beef, Mongolia is a key partner with Russia annually exporting USD 7.5 million or 2.9 thousand tons to Russia, $2 \%$ of imported products. As for horses, in Russia USD 4.5 million or 1.7 thousand tons, and China's USD 2.5 million or 2.4 thousand tons. This is horse meat imports of $6 \%$ for Russia and $72 \%$ for China. On average, about 2.9 million animals/year are from China to China USD or 3.5 thousand tons of hides and 2.6 million USD or 2.5 thousand tons of unprocessed hides. China of these products each year an average of USD 2306 million, 1411 million the dollar imports the world's largest raw material big buyer. Italy imports the above the second largest in the world after the US is USD 1140 million and imports USD 1.3 million. Our country is in Italy an average of 63.3 thousand USD or 30 tons of unprocessed hides, 3.6 million USD or 1.3 million tons of hides were processed which is $0.01 \%$ of imported raw and processed hides and $0.03 \%$ respectively. This rate will increase significantly opportunity is observed.

In addition, China has 5.9 million USD sheep without a dimple. Fine and coarse hair animals of USD 72.8 thousand the export of non-combed hair into the country's imports of these products $0.2 \%$ and $83.3 \%$ respectively. Combination of animal hair imports of the United States (USD 4.571 million), Switzerland (USD 556 million), Germany (USD 309 million), Italy (USD 82 million) are the major countries in the world. Although the export of wool, the size of the textile cloth is low, on the other hand, these countries 589 the world's major importers of products. For example, Italy average annualized US USD 417.1 million, Germany USD 206.6 million, Korea USD 163.2 million, China USD 125.2 million and Japan import USD 90 million respectively. It is the export to Italy, Germany, Korea, and Japan of wool and cotton textile products which has the greatest opportunity.

4) For our non-dehydrated carpet and other textile products: The comparative advantages are weak and in 2013 China the average is USD 510 thousand or 42 tons, in Russia \$ seventy-three thousand or 6 tons products were exported. In this area our textile wall polishing, lanterns, rigs, electric woven tubes, and pipes can be produced and exported. These are the main products. Importers are the US, China, Russia, Germany and Japan. Wool, cashmere and textile products are the good competitors of our country for a relative advantage index, but improved manufacturing technology, wool, and cashmere that can meet the demands of the world market will increase exports of products. For example, for women's cashmere and cashmere shirts, there are large markets such as USA, Germany and Japan. It is necessary to establish and export our country today. Imports 
are only $0.0003 \%$ the United States and $0.01 \%$ Japan. It is a result of anxiety.

According to the above analysis, our export of agriculture has the largest and most important advantage of all products. In the external market the product that can expand its market volume is meat and meat products and wool and cashmere products. These products that are traded to meet the requirements and standards for export to partner countries will be presented in the following section.

5) Export of agricultural products with comparative advantages: The opportunity to increase from the relative advantages (RCA) index found in the preceding section Mongolia has a comparative advantage in our country and abroad to increase volume. Agricultural products are meat, meat products and wool and cashmere products. Export of these products in this section we will learn more about opportunities to increase.

\section{F. Opportunity to Increase Exports of Meat and Meat Products}

As long ago as the former Soviet Union, Mongolia had an average annual production of over 60 thousand tons of meat (UNDP, 2009). In 2014, 2.6 thousand tons of meat was exported.[10] Within this context, Mongolia is a major trading partner. Select from China, Russia, and Japan and give them meat and meat products and study the requirements and standards of imports. Chinese food hygiene imports the requirements are relatively small compared to the Russia and Japan and the control of the product and it is necessary to create a number of documents when conducting the examination. This process requires time and procedural uncertainty can cause exporters costs. But with an average tariff of $15.8 \%$ in China on our agricultural products, there is a favorable opportunity.

But Japanese food safety standards are very high and our meat and meat products do not meet this requirement. The country also sells $38.5 \%$ of beef in cattle, but sheep and horses. There is no meat tax. This is the area in which our country builds its quality of meat and it is possible to increase exports (Enkhbold, V., Nomintsetseg, U., Bolor, B., 2015). How much can meat exports increase? Cattle, horses, and sheep meat export potential or domestic capacity maintains the level of livestock in 2014 and reduce it in 2015. Calculate how much size can be exported. In 2015, livestock the number is calculated as the previous year, considering domestic consumption find net growth in the head and export it by cargo weight, determine the possible amount. In other words, in 2015 the livestock the remainder of the domestic need to hold the population at the level of the previous year to export.

According to the calculations, 56.6 thousand tons of mutton, 68.6 thousand tons of beef and 47.3 thousand tons of horse meat 591 It is possible to earn a total of USD 633 million from exports.

This estimate does not consider the environmental impacts of the dud and drought natural disasters; the number of livestock increases can be dramatically changed. Also, the export price is USD 2.9/kg and beef USD 4.9/kg and horse meat at USD $2.8 / \mathrm{kg}$. When domestic prices are higher export opportunities will be reduced. Currently sheep mutton USD $3.8 / \mathrm{kg}$ (7490 MNT) or 35\% higher than the world market price. Beef monolithic meat is USD 5.0/kg (9835 MNT) or $10 \%$ higher than world prices is 14 . Even in recent years, the depreciation of the MNT has been weakening and the world market meat prices have risen, but the domestic price of meat is still high compared to the world market price.

At the regional level, especially the neighboring economies, at the same time, the average demand for meat and dairy products will increase. However, for Russia, EU, USA, Canada, Norway and Australia, food hygiene standards are prohibit importing foodstuffs from countries high and low competitiveness of our meat exports and reduce the opportunity to increase. Therefore, we must improve product hygiene standards, and domestic meat prices to improve the productivity of livestock in order to keep costs lower than foreign prices, Livestock production needs to be increased.

\section{G. Opportunity to Increase Exports of Cashmere and Cashmere Products}

Mongolian cashmere accounts for $88 \%$ of agricultural exports and total exports 5\%. Mongolia supplies $21 \%$ of global cashmere, after China.[11] For unrefined and semifinished (washed, de-haired) cashmere the relative comparative advantage of exports is that of previous analyzes has been shown. Also, domestic consumption is low; the domestic price of cashmere was shown earlier that the value of the foreign market depends directly on the price. But unprocessed and semi-finished cashmere exports in 2014 to USD 286 million, cashmere exports will not reach $10 \%$. For exporters of Mongolian wool and cashmere products the problems are: Firstly, Mongolia is small and landlocked; secondly, constant large quantities cannot be supplied and thirdly, quality is poor.

For example, large quantities of ready-made products in the world market mean poor opportunities to produce, and advertisements are weak. Mongolia of which 1.6 million cashmere products are manufactured and foreign the ability to supply customers with large quantities of orders is limited. China is the main competitor because of the poor quality of cashmere, they are often excluded from producing luxury products (G. Yondonambaa, 2015). The cashmere quality is the world's average cashmere in terms of the three major suppliers of cashmere markets, Mongolian cashmere 16.016.8 microns for Chinese cashmere 15.6 microns for cashmere 17.4 microns. (e.g., Gombat, 2012).

With this quality, the price is fixed in the market. For example, Schneider cashmere market indicator is 15. As of the end of July 2015 Chinese cashmere 124.7 while Mongolian cashmere 88.8 and Iranian cashmere 85.9. In other words, Mongolia's cashmere price is $40 \%$ cheaper than the Chinese price.[12]

From 1958 to 1965, cashmere goats were bred. In 19651971, hybrid goats were multiplied created a suitable goat flock, and it was new from 1971-1983. Multiplication of goat 
breeds since 198315 Schneider Cashmere Market Indicators are based on USD, but are not price-free and do not depend on exchange fluctuations. 593 define the chemistry and determine breeding work as a result of Mongolian cashmere at the end of the 1980s the quality improved dramatically and it was cheaper than the Chinese cashmere price in 1988-1990 by $8-10 \%$ (Maah's Research Institute, 2013), in the 1990's improved livestock products were made by privatizing livestock as opposed to early poor state-run jobs and veterinary services. [13]

The quality of cashmere is no longer good and has deteriorated. Mongolian cashmere has not been able to produce high-end luxury products which in turn means the development of cashmere production is negative (World Bank, 2003). For herders to improve the competitiveness of Mongolian cashmere producers and policy makers, i.e. goats it is important to focus on the advertisement of cashmere products. For instance, herders are domestic producers of raw material quality. To improve goat breeds and to paint the cashmere we must improve the water quality used (very soft water is required). Chemistry is essential for maintaining wool and cashmere sustaining supply of goods and domestic spinning capacity increase, and improves the quality of spinning (G.Ganbat, 2012).

State regulations and policy are important to improve the quality of cashmere. For example, in addition to focusing on breeds, livestock cull will be needed to support the program. When the goat ages the quality of the cashmere is deteriorating, and its composition is more than 3-4 years old, taxation, etc. (World Bank, 2003). Growing goat numbers have a negative impact on the environment. For example, goats are the most devastating to grass when compared with the other five eatables, which affects plants that grow on some rocks. Some goats also have sharp hoofs and it affects the plants. It also occurs in the Gobi region spring increase of goat dust and its impacts - The World Bank's Environmental Monitoring reported (World Bank, 2002).

Therefore, improving the quality of goat cashmere, rather than raising the number of goats will increase the export price, and the cashmere is not in the form of raw materials we need to pay attention to manufacturing products. Cashmere by the end of the year, delivering the quality to the 1989 level can increase income by $32 \%$. For example, income growth is $32 \%$ in 2014 and export earnings of cashmere were USD 92 million, $0.8 \%$ of GDP.

The priority is to increase productivity within the agricultural policy. It might be effective to put it into place. Krugman $(1996,2001)$ stated in a country it is not only inconvenient to be competitive in terms of export competitiveness but dangerous. Domestic and international rather than supporting economic growth to the competition, which is determined by trade surplus the desire, can lead to trade wars or even currency wars, he highlighted. Porter and Krugman are real competition productivity measurements and not productive the increase is also a key objective (Latruffe, 2010). Growth in agricultural productivity increases real income and creates jobs. The impact of the multiplier on non-farm businesses in rural areas and food is that it affects the price of the commodity, thereby reducing poverty.[14]

\section{CONCLUSION}

The competitiveness of the agricultural sector is widely measured internationally by the Index of horse meat, beef, leather, cashmere. Cashmere products have a comparative advantage. It is necessary to pay attention to hygiene of meat to increase exports of these products (for example, the establishment of an infectious disease prevention system), and meat keeping domestic prices relatively low, as well as trading partner countries on reducing import tariffs from Mongolian meat and meat production. Livestock product prices, especially meat prices are higher than foreign prices, and cashmere price is determined by external prices, the price increases are also revenue not sustainable.

\section{REFERENCES}

[1] Joe Dewbre, Dalila Cervantes-Gody, Silvia Sorescu. (2011) Agricultural Progress and Poverty.

[2] Swiss Agency for Development and Cooperation. (May 2015) National Report on Rangeland Health of Mongolia. SDC

[3] Latruffe, L. (2010). Competitiveness, Productivity, and Efficiency in the Agricultural and Food Sectors. OECD Food, Agriculture and Fisheries Papers, p. 30.

[4] Janet Dwyer et all. (2012). How to Improve the Sustainable Competitiveness and Innovation of the EU Agricultural Sector? Brussels: European Parliament, Policy Department.

[5] C.Martin Webber, Partrick Labaste. (2010). Building Competitiveness in Africa's Agriculture: A Guide to Value Chain Concepts and Applications. World Bank.

[6] Mongolian Statistical Yearbook (2014)

[7] R.Kaplan, D.Norton. (2008). The Execution Premium: Linking Strategy to Operations for Competitive Advantage. Harvard Business School Publishing.

[8] Smith, A. (1776). An Inquiry into The Nature and Causes of the Wealth of Nations.

[9] Bela, B. (1965). Trade Liberalization and Revealed Comparative Advantage. Manchester School of Economic and Social Studies No.33, 99-123.

[10] UNDP. (2009). Trade Policy and Human Development in Mongolia Ulaanbaatar: Munkhiin Useg Group.

[11] Enkhbold, V., Nomintsetseg, U., Bolor, B. (2015). Research Analysis of Mongolian Export Oriented Meat Products.

[12] Shneider. (2015). http://www.gschneider.com/. Retrieved 2015 year 0904 from http://www.gschneider.com /: http://www.gschneider.com/

[13] Mongolia Livestock Sector Study VOLUME I - SYNTHESIS REPORT (2009)

[14] Schneider, K., \& Gugerty, M. K. (2011). agricultural Productivity and Poverty Reduction: Linkages and Pathways. The Evans School Review, 56-69. 